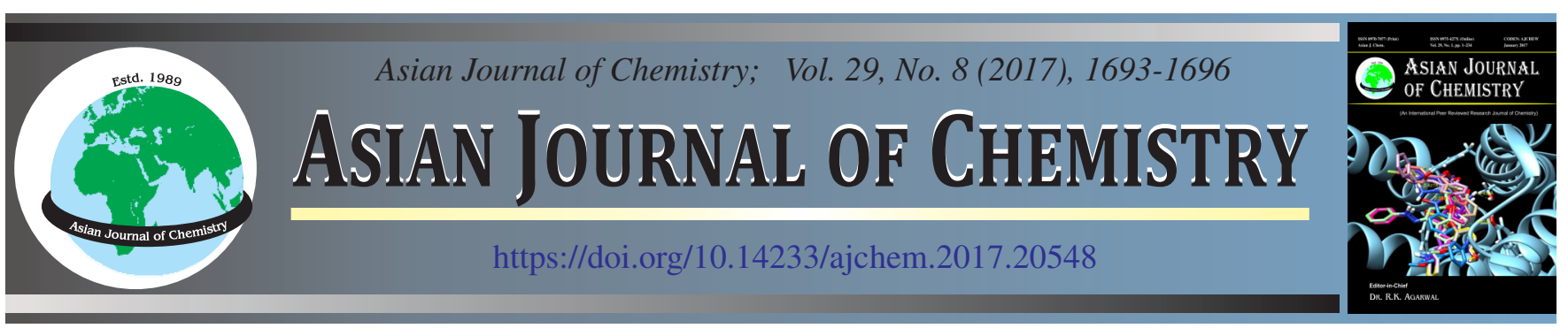

\title{
Green Synthesis of Gold Nanoparticles Using Cinnamomum verum, Syzygium aromaticum and Piper nigrum Extract
}

\author{
M. Sharma ${ }^{1, *}$, M. PATHAK ${ }^{1}$, H. OJHA ${ }^{2}$ and B. Roy ${ }^{1}$
}

${ }^{1}$ Department of Chemistry, Miranda House, University of Delhi, Delhi-110 007, India

${ }^{2}$ Division of CBRN Defence, Institute of Nuclear Medicine and Allied Sciences, Delhi-110 054, India

*Corresponding author: E-mail: malti.sharma@mirandahouse.ac.in

Received: 27 January 2017;

Accepted: 10 April 2017;

Published online: 12 June 2017;

AJC-18423

\begin{abstract}
Recently, nanoparticles have gained significance in the field of biomedicines but use of the chemical reducing agent in their preparation, limit it in the field of biomedicine. Hence, we have synthesized gold nanoparticles (AuNPs) by stirring the appropriate volume of aqueous extract of Cinnamomum verum (dried bark), Syzygium aromaticum (dried flower buds) and Piper nigrum (dried berries) with aqueous solution of chloroauric acid $\left(\mathrm{Au}^{3+}\right)$ by greener method. The UV-visible spectrum of AuNPs showed a broad band in the region 543-546 nm corresponding to the surface plasmon resonance band (SPR) of AuNPs. The position of band did not change even after 2 weeks, depicting the stability of prepared nanoparticles. FESEM and DLS confirmed their size and dispersity. Furthermore, the rate of formation of nanoparticles using different spice extracts as reducing agent give an indication towards the concentration of active components present in them i.e. Syzygium aromaticum is the better reducing agent as compared to Cinnamomum verum and Piper nigrum.
\end{abstract}

Keywords: Gold nanoparticles, Syzygium aromaticum, Cinnamomum verum, Piper nigrum, Surface plasmon resonance, FESEM, DLS. ᄂ - - - - - - - - - - - - - - - - - - - - - - - - - - - -

\section{INTRODUCTION}

Gold nanoparticles (AuNPs) are known from ancient times and have been used in many applications especially as colour pigments in lustre and glass technology. They might have been produced accidentally or by weathering, volcano eruptions, microbial processes. The best example is found in fourth century CE, when Romans manufactured Lycurgus Cup currently kept in British Museum [1], which appears green in colour in reflected light and changes to red when illuminated from inside because of silver-gold alloy nanoparticles mixed with the glass. Red colloidal gold is still in use in Indian Aurvedic medicines [2] as Swarna Bhasam and Makaradhwaja. Aurum Potabile (drinkable colloidal gold) was used in Europe in 16th century to cure many diseases [3].

In last 20 years, the nanomaterial research which was initially limited to material science is now seen in almost every field of science. The unusual property of nanoparticle is due to its high surface to volume ratio which makes them unique in the area of research. Because of the chemical inertness, high sensitivity for detection and high stability in liquid and solid form, lot of work is being done on AuNPs. The first AuNPs was described by Turkevitch [4] in 1951 and further developed by Frens [5] in 1973 by heating a solution of $\mathrm{HAuCl}_{4}$ in presence of sodium citrate.
These days, a variety of methods are available for the preparation of AuNPs in literature [6-9]. Most common method is reduction method using chemical or natural materials as reducing agent. These natural materials include plant extracts [10-13] or micro-organisms [14-17]. Chemical reducing agents like hydrogen, ethylene glycol, ethanol, sodium citrate, sodium borohydride, hydrazine hydrate etc. are toxic, hazardous to the environment and impure nanoparticles obtained in most. Use of chemical reducing agents limits their use in the biomedical field especially in clinical fields. Therefore, there is a growing interest in the green synthesis of nanoparticles as they provide superior material properties with functional versatility. In this connection, we have prepared AuNPs using aqueous extracts of medicinal plants Cinnamomum verum, Syzygium aromaticum and Piper nigrum. These reactions are ecofriendly, easily performed in the undergraduate college chemistry laboratory and mild reaction conditions are required. The reducing agents chosen for AuNPs preparation are low-cost, easy to store and available throughout the year. Syzygium aromaticum [18] is known for its antimicrobial, antifungal, antiseptic, antiviral and stimulant properties. The main chemical component present is Eugenol. Cinnamomum verum bark contains major components [19] cinnamaldehyde and eugenol. It lowers blood sugar levels, reduces heart disease risk factors and has other health benefits. Piper nigrum have 
anti-carcinogenic, antioxidant, anti-inflammatory properties and ability to stimulate digestion. It has been effectively used as one of the most important constituents in the medical field worldwide. It contains piperidines, pyrrolidines and amides [20].

\section{EXPERIMENTAL}

The spices were purchased from local market. Chloroauric acid trihydrate $\left(\mathrm{HAuCl}_{4} \cdot 3 \mathrm{H}_{2} \mathrm{O}\right)$ (Fisher Scientific) of $99.8 \%$ purity was used for gold nanoparticles preparation. The water used for the synthesis was 18 Mega ohm MilliQ grade water derived from Millipore water system (Elix 3, Millipore Corp USA). Cary 100 (BIO UV-visible spectrophotometer, Varian, Australia) was used for characterization of prepared nanoparticles. Morphological details of the AuNPs were analyzed by field emission scanning electron microscopy FESEM (JEOL JSM-6360, Mira-3, Tescan, Brno-Czech Republic). Evaluation of size and dispersity of the particles was carried out using a Zetasizer analyzer (Zetasizer 3600 ) at $25^{\circ} \mathrm{C}$ with a scattering angle of $90^{\circ}$ (Nanosizer/Zetasizer ZS Malvern Instruments, Worcestershire, UK).

Preparation of spice extract: Spices were washed thoroughly with Milli Q water and then dried in oven. The dried spices were finely powdered using mortar and pestle. 0.5 and $1 \%$ extract of spices powder were prepared by boiling for 10 min in Milli Q water. The extracts were filtered with Whatman filter paper number 1 and the residual material was discarded. The filtered extracts were stored in the refrigerator at $4{ }^{\circ} \mathrm{C}$ for use as reducing agent in the synthesis of AuNPs. We preferred freshly prepared spice extract solutions in the preparation.

Green synthesis of AuNPs: $10 \mathrm{~mL}$ of $1 \mathrm{mM}$ aqueous solution of chloroauric acid was added to $30 \mathrm{~mL}$ Milli Q water in a conical flask and stirred with heating using magnetic stirrer at a temperature of around $50{ }^{\circ} \mathrm{C}$. After $2 \mathrm{~min}, 10 \mathrm{~mL}$ of $1 \%$ Cinnamomum verum extract was added to the conical flask containing chloroauric acid solution. The progress in conversion of gold ions to AuNPs was monitored by observing the colour change and scanning the UV-visible spectra. The time taken for conversion to AuNPs was also noted. Similar procedure was applied for the preparation of AuNPs using $1 \%$ Piper nigrum aqueous extract but with Syzygium aromaticum extract only $1 \mathrm{~mL}$ of $0.5 \%$ extract was used.

\section{RESULTS AND DISCUSSION}

Synthesis of gold nanoparticles (AuNPs): Gold nanoparticles were prepared in the lab by stirring aqueous extracts of Cinnamomum verum (dried bark), Syzygium aromaticum (dried flower) or Piper nigrum (dried fruit) with chloroauric acid solution at temperature around $50{ }^{\circ} \mathrm{C}$.

Yellow coloured solution of chloroauric acid changed to blue to violet and finally to red (Fig. 1) over the monitoring time period that was 15 min on slow addition of aqueous solution of spice extract which confirmed the formation of AuNPs [21,22]. The medicinal spice extracts used contain amino acids, essential oils, carbohydrate derivatives, resins, glycosides, phenylpropanoids etc. These active components not only act as a reducing agent but also as capping agent to prevent the agglomeration of prepared AuNPs [23] which

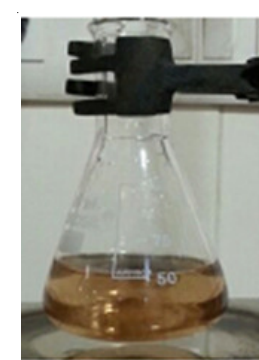

(A)

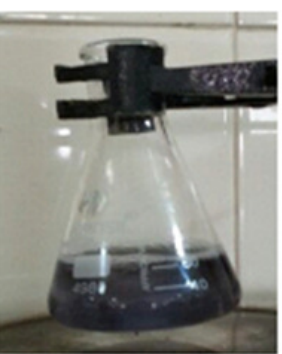

(B)

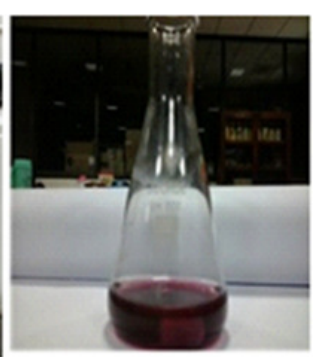

(C)
Fig. 1. Colour change during the preparation of AuNPs using Cinnamomum verum after (a) $5 \mathrm{~min}$, (b) $10 \mathrm{~min}$ and (c) $15 \mathrm{~min}$

increase their stability. The colour change occurred due to the reduction of $\mathrm{Au}^{3+}$ to $\mathrm{Au}^{0}$. The size and colour of AuNPs depend upon the concentration of reducing agent [24] and chloroauric acid solution as well as reaction temperature and order of addition of reagents [25]. Colour changes from blue to violet to finally red [26] indicate the formation of smaller nanoparticles. Gold nanoparticles were prepared by using $10 \mathrm{~mL}$ of $1 \%$ Cinnamomum verum and Piper nigrum whereas $1 \mathrm{~mL}$ of $0.5 \%$ Syzygium aromaticum extract was used. Reaction was tried using 5 or $10 \mathrm{~mL}$ of $1 \%$ Syzygium aromaticum extract but precipitation occurred after 2 min whereas the colour of the solution remained red. This may be due the excess concentration of active component required for reduction of $\mathrm{Au}^{3+}$ present in the solution i.e. why we have reduced the concentration of Syzygium aromaticum extract.

Surface plasmon resonance (SPR) studies: UV-visible spectrophotometry technique is generally used to characterize colloidal solution of AuNPs. The prominent feature of noble metal nanoparticles such as gold and silver are their surface plasmon resonance (SPR) which exhibit as a sharp and intense absorption band in the visible region. The shift in surface plasmon resonance band towards red or blue end is dependent on the particle size, state of aggregation and polarity of the micro-environment. It gives ideas about the formation of nanoparticles and their size as well as dispersity. Further, relative uniformity of the particles or the range of the particles can be guessed by the width of the absorption spectra; the sharper the band, more the uniformity in the particles [27]. Gold nanoparticles prepared by three extracts exhibit a surface plasmon resonance band (Fig. 2) in the range 543-546 nm with absorbance ranging from 0.63-0.85 (Table-1). The broad absorption

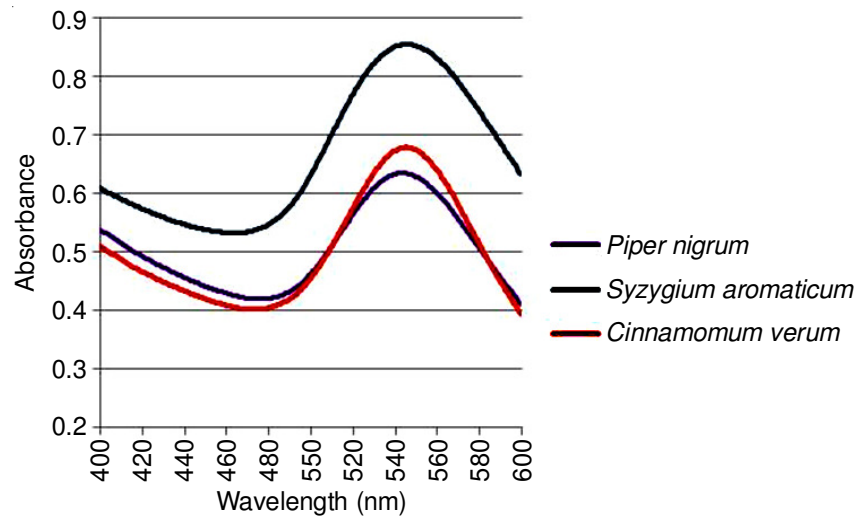

Fig. 2. UV-visible spectra of AuNPs prepared by Cinnamomum verum, Syzygium aromaticum and Piper nigrum extract 


\begin{tabular}{lcc}
\hline \multicolumn{4}{c}{ TABLE-1 } \\
\multicolumn{2}{c}{ SURFACE PLASMON RESONANCE BAND OF AuNPs } \\
\hline \multicolumn{1}{c}{ Spice extract used } & $\lambda_{\max }(\mathrm{nm})$ & Absorbance \\
\hline Cinnamomum verum & 545 & 0.67 \\
Syzygium aromaticum & 546 & 0.85 \\
Piper nigrum & 543 & 0.63 \\
\hline
\end{tabular}

band around 543-546 nm confirmed the formation of polydispersed AuNPs with average size less than $55 \mathrm{~nm}$ [28] which is supported by the literature value [23].

One absorption band in UV-visible spectra indicated same shape [26] of the nanoparticles. Gold nanoparticles prepared by these three extracts exhibit exactly same coloured solution and their $\lambda_{\max }$ values are also same suggesting almost same size of nanoparticles.

Stability of prepared nanoparticles was examined by noting the absorbance and $\lambda_{\max }$ after every $12 \mathrm{~h}$ for 2 weeks and it was found that there was no change in their $\lambda_{\max }$ and absorbance value. On comparing the UV-visible spectra of AuNPs prepared by these three extracts, it was found that the high yield of nanoparticles were formed with Syzygium aromaticum as compared to Cinnamomum verum and Piper nigrum which was indicated by their high absorbance (Fig. 2) value even using less concentrated ( $1 \mathrm{~mL}$ of $0.5 \%$ ) extract solution. This may be due to the presence of either high concentration of active component in the extract required for reduction or good reducing agent.

Field emission scanning electron microscopy (FESEM) studies: FESEM is the most adapted technique in the characterization of nanoparticles. It gives size, shape and morphologies of prepared nanoparticles and their surfaces. FESEM images showed presence of small square (Fig. 3(a)) and rectangular [Fig. 3(b)] AuNPs prepared by Syzygium aromaticum and Piper nigrum extract, respectively. Besides this, FESEM images confirmed that both types of AuNPs are looking in polydispersed state.

FESEM images (Fig. 3) confirmed the role of active components present in the spice extracts as reducing as well as stabilizing agent, which prevent the AuNPs from agglomeration as indicated by separated particles.

Size distribution by dynamic light scattering (DLS): Dynamic light scattering technique has been used to determine the size of the particles in the colloidal suspension. Particle size distribution curve (Figs. 4 and 5) reveals that AuNPs obtained were polydispersed in nature with PDI 0.50-0.52 (Tables 2 and 3). This was earlier indicated by broad surface plasmon resonance absorption band. Dynamic light scattering results are generally expressed in terms of Z-average (d.nm) values. Since calculation of Z-average is obtained using mathematically stable least square fitting technique, so Z-average values are insensitive towards to experimental noise. In the present study, the Z-average values as determined ranged from 2.9-
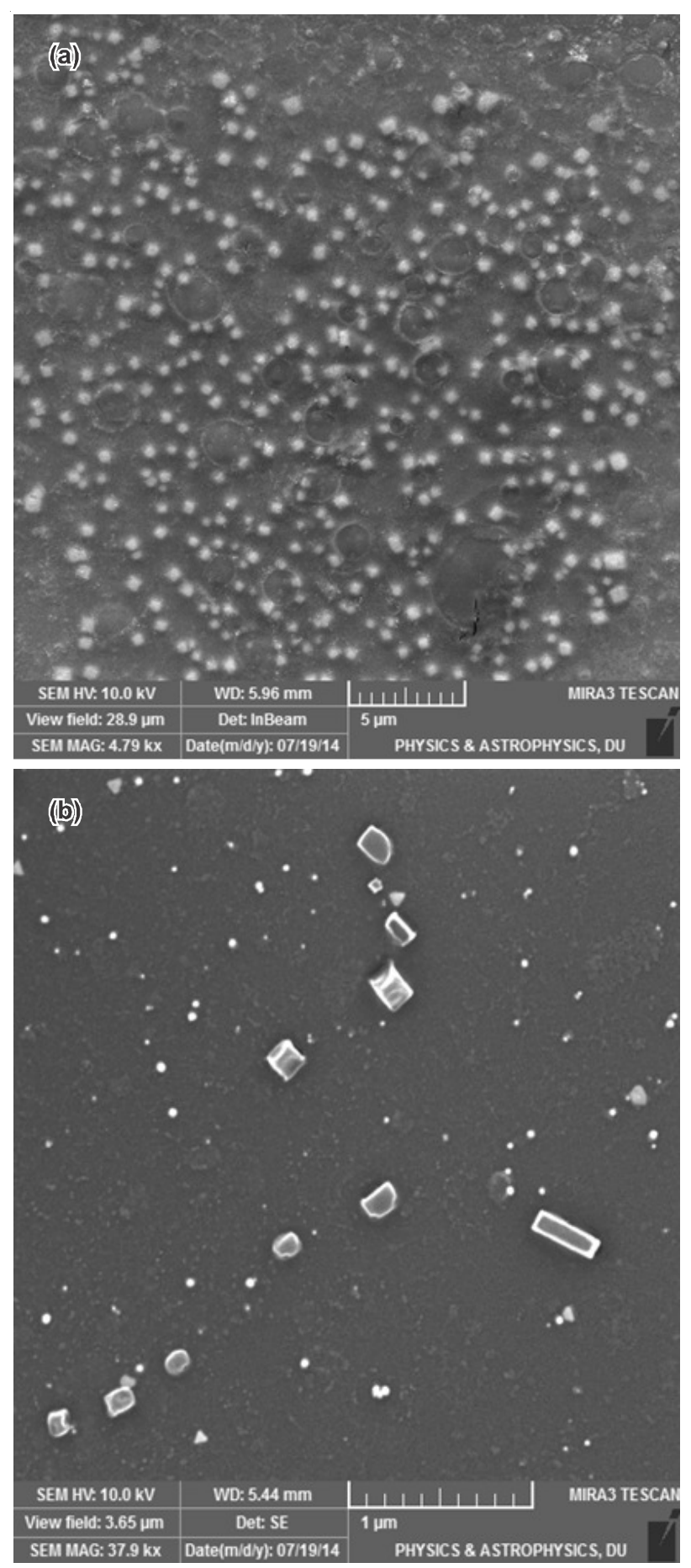

Fig. 3. FESEM images of AuNPs prepared by (a) Syzygium aromaticum (b) Piper nigrum

in 3.6 (Tables 2 and 3) indicating almost same size of AuNPs prepared by Cinnamomum verum and Piper nigrum. In Fig. 4 there is small peak (intensity $18.0 \%$ ) of smaller particles which was not sufficient to induce change in the UV-visible spectra.

TABLE-2

SIZE DISTRIBUTION ANALYSIS OF AuNP PREPARED BY Cinnamomum verum EXTRACT

\begin{tabular}{cccccc}
\hline Parameter & Value & Peak No. & Peak diameter $(\mathrm{nm})$ & Peak intensity $(\%)$ & Peak width $(\mathrm{nm})$ \\
\hline Z-average $($ d.nm) & 2.937 & Peak no. 1 & 6.5170 & 82.0 & 3.249 \\
PDI & 0.524 & Peak no. 2 & 0.9608 & 18.0 & 0.293 \\
Intercept & 0.764 & Peak no. 3 & 0.0000 & 0.0 & 0.00 \\
\hline
\end{tabular}


TABLE-3

SIZE DISTRIBUTION ANALYSIS OF AuNPs PREPARED BY Piper nigrum EXTRACT

\begin{tabular}{cccccc}
\hline Parameter & Value & Peak No. & Peak diameter $(\mathrm{nm})$ & Peak intensity $(\%)$ & Peak width $(\mathrm{nm})$ \\
\hline Z-average $($ d.nm) & 3.602 & Peak no. 1 & 6.481 & 100.0 & 3.792 \\
PDI & 0.500 & Peak no. 2 & 0.000 & 0.0 & 0.00 \\
Intercept & 0.803 & Peak no. 3 & 0.000 & 0.0 & 0.00 \\
\hline
\end{tabular}

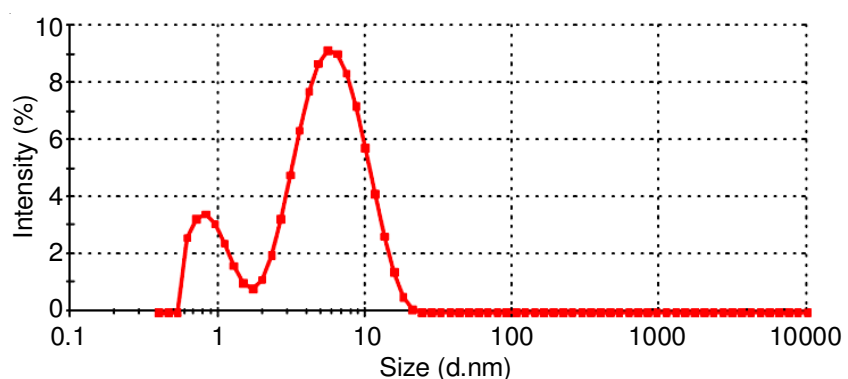

Fig. 4. Size distribution intensity graph of AuNPs prepared by Cinnamomum verum extract

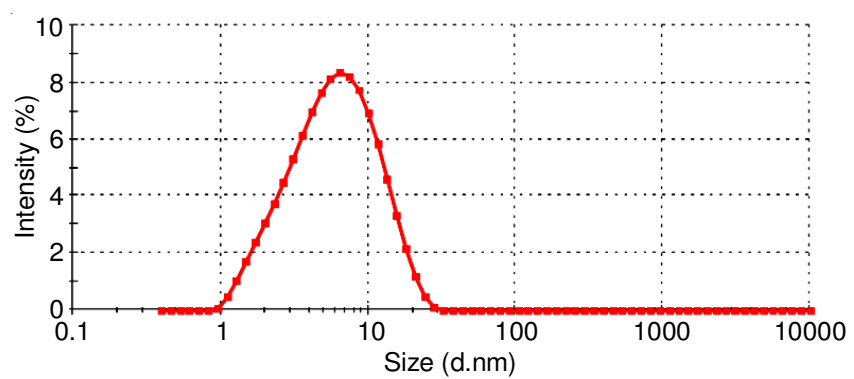

Fig. 5. Size distribution intensity graph of AuNPs prepared by Piper nigrum extract

\section{Conclusion}

Gold nanoparticles prepared using medicinal plants are stable. Active components present in these medicinal plant extracts play important role in the reduction and stabilization as well as prevent them from agglomeration. Average size and dispersity as confirmed by UV-visible spectra was found to be less than $55 \mathrm{~nm}$ and polydisperse. Further, FESEM confirmed the size range, polydispersity and existance of nanoparticles as separated particles. Dynamic light scattering confirmed their polydispersity and size in the range between 2.9-3.6 nm.

\section{ACKNOWLEDGEMENTS}

The authors sincerely thank Dr. Pratibha Jolly, Principal Investigator, D.S. Kothari Centre for Research and Innovation, Miranda House and Head, Department of Chemistry, University of Delhi, Delhi, India for providing support and equipment facilities. Thanks are also due to Head, Department of Physics \& Astrophysics, University of Delhi for providing the use of FESEM.

\section{REFERENCES}

1. I. Freestone, N. Meeks, M. Sax and C. Higgitt, Gold Bull., 40, 270 (2007); https://doi.org/10.1007/BF03215599.

2. D.A. Atwood, Sustainable Inorganic Chemistry, John Wiley \& Sons: New York, United States (2016).
3. W. Caseri, Macromol. Rapid Commun., 21, 705 (2000); https://doi.org/10.1002/1521-3927(20000701)21:11<705::AIDMARC705>3.0.CO;2-3.

4. J. Turkevich, P.C. Stevenson and J. Hillier, Discuss. Farad. Soc., 11, 55 (1951); https://doi.org/10.1039/df9511100055.

5. G. Frens, Nat. Phys. Sci. (Lond.), 241, 20 (1973); https://doi.org/10.1038/physci241020a0.

6. K. Okitsu, Y. Mizukoshi, T.A. Yamamoto, Y. Maeda and Y. Nagata, Mater. Lett., 61, 3429 (2007); https://doi.org/10.1016/j.matlet.2006.11.090.

7. A. Plech, V. Kotaidis, A. Siems and M. Sztucki, Phys. Chem. Chem. Phys., 10, 3888 (2008).

8. N.S. Yusof and M. Ashok Kumar, ChemPhysChem, 16, 775 (2015); https://doi.org/10.1002/cphc.201402697.

9. A.N. Madu, P.C. Njoku, G.A. Iwuoha and U.M. Agbasi, Int. J. Phys. Sci., 6, 635 (2011).

10. K. Wani, A. Choudhari, R. Chikate and R.K. Ghanekar, Carbon Sci. Technol. (Paris), 5, 203 (2013).

11. K.D. Arunachalam, S.K. Annamalai and S. Hari, Int. J. Nanomedicine, 8, 1307 (2013); https://doi.org/10.2147/IJN.S36670.

12. S.A. Aromal, V.K. Vidhu and D. Philip, Spectrochim. Acta A Mol. Biomol. Spectrosc., 85, 99 (2012); https://doi.org/10.1016/j.saa.2011.09.035.

13. A.K. Mittal, Y. Chisti and U.C. Banerjee, Biotechnol. Adv., 31, 346 (2013); https://doi.org/10.1016/j.biotechadv.2013.01.003.

14. N. Pantidos and L. Horsfall, J. Nanomed. Nanotechnol., 5, 233 (2014); https://doi.org/10.4172/2157-7439.1000233.

15. X. Li, H. Xu, Z.S. Chen and G. Chen, J. Nanomater, 2011, 1 (2011).

16. U. Shedbalkar, R. Singh, S. Wadhwani, S. Gaidhani and B.A. Chopade, Adv. Colloid Interface Sci., 209, 40 (2014); https://doi.org/10.1016/j.cis.2013.12.011.

17. R. Ramanathan, M.R. Field, A.P. O'Mullane, P.M. Smooker, S.K. Bhargava and V. Bansal, Nanoscale, 5, 2300 (2013); https://doi.org/10.1039/C2NR32887A.

18. M.I. Nassar, A.H. Gaara, A.H. El-Ghorab, A.-R.H. Farrag, H. Shen, E. Huq and T.J. Mabry, Rev. Latinoam. Quím., 35, 47 (2007).

19. P.A. Paranagama, S. Wimalasena, G.S. Jayatilake, A.L. Jayawardena, U.M. Senanayake and A.M. Mubarak, J. Natl. Sci. Found. Sri Lanka, 29, 147 (2001).

20. M. Meghwal and T.K. Goswami, Scient. Rep., 1, 172 (2012); https://doi.org/10.4172/scientificreports.172.

21. K. Lata, A.K. Jaiswal, L. Naik and R. Sharma, Nano Trends: J. Nanotechnol. Appl., 17, 1 (2015).

22. M. Sharma, M. Pathak, B. Roy, A. Chand, G. Dhanda, N. Abbasi and G. Panchal, J. Mater. Nanosci., 3, 8 (2016).

23. I.V. Safenkova, A.V. Zherdev and B.B. Dzantiev, J. Immunol. Methods, 357, 17 (2010); https://doi.org/10.1016/j.jim.2010.03.010.

24. P. Zhou, Y. Lu, J. Zhu, J. Hong, B. Li, J. Zhou, D. Gong and A. Montoya, J. Agric. Food Chem., 52, 4355 (2004); https://doi.org/10.1021/jf0499121.

25. S. Eustis and M.A. El-Sayed, Chem. Soc. Rev., 35, 209 (2006); https://doi.org/10.1039/B514191E.

26. X. Huang and M.A. El-Sayed, J. Adv. Res., 1, 13 (2010); https://doi.org/10.1016/j.jare.2010.02.002

27. H. Verma, P. Singh and R.M. Chavan, Vet. World, 7, 72 (2014); https://doi.org/10.14202/vetworld.2014.72-77.

28. S. Link and M.A. El-Sayed, J. Phys. Chem. B, 103, 4212 (1999); https://doi.org/10.1021/jp9847960. 